\title{
Automatic sleep scoring in normals and in individuals with neurodegenerative disorders according to new international sleep scoring criteria
}

\author{
Jensen, Peter S.; Sørensen, Helge Bjarup Dissing; Jennum, P. J.
}

Published in:

European Journal of Neurology

Link to article, DOI:

10.1111/j.1468-1331.2010.03233.x

Publication date:

2010

Document Version

Publisher's PDF, also known as Version of record

Link back to DTU Orbit

Citation (APA):

Jensen, P. S., Sørensen, H. B. D., \& Jennum, P. J. (2010). Automatic sleep scoring in normals and in individuals with neurodegenerative disorders according to new international sleep scoring criteria. European Journal of Neurology, 17(Supplement s3), 624. https://doi.org/10.1111/j.1468-1331.2010.03233.x

\section{General rights}

Copyright and moral rights for the publications made accessible in the public portal are retained by the authors and/or other copyright owners and it is a condition of accessing publications that users recognise and abide by the legal requirements associated with these rights.

- Users may download and print one copy of any publication from the public portal for the purpose of private study or research.

- You may not further distribute the material or use it for any profit-making activity or commercial gain

- You may freely distribute the URL identifying the publication in the public portal 


\section{P2754}

\section{Restless legs syndrome in depression}

$\underline{\text { S. Happe' }}{ }^{1}$ B.T. Baune ${ }^{2}$, M. Lanz ${ }^{3}$, K. Berger', M. Hornyak

'Department of Clinical Neurophysiology, Klinikum BremenOst/University of Göttingen, Bremen, Germany, 'Department of Psychiatry, James Cook University Queensland, Townsville, QLD, Australia, 'Epilepsy Center, Department of Neurosurgery, University of Freiburg, Freiburg im Breisgau, 'Institute of Epidemiology and Social Medicine, University of Münster, Münster, 'Interdisciplinary Pain Center and Department of Psychiatry and Psychotherapy, University of Freiburg, Freiburg im Breisgau, Germany

Objective: Symptoms of depression and anxiety are frequent in patients with restless legs syndrome (RLS). Recent community-based studies have shown associations between RLS and major depressive disorder and panic disorder. However, little is known whether patients with a manifest depressive disorder have an increased prevalence of RLS and whether there is an association to different depressive disorders.

Patients and methods: Three psychiatry departments in two countries (Germany and Australia) each recruited 100 consecutive patients with current depression. All patients filled in a standardized questionnaire including diagnostic questions for RLS, a depression scale (CESD), and the RLS severity scale (IRLS) if RLS was present. The treating doctors filled in a second standardized questionnaire including RLS-diagnostic questions and comorbidities.

Results: Altogether, 290 questionnaires could be evaluated, 190 in Germany (96 in Bremen, 94 in Freiburg) and 100 in Australia. The Australian patients were younger than the German patients $(45.4 \pm 13.8$ vs. $49.7 \pm 15.0$ years, $p=0.018)$, the gender distribution was not different $(p=0.71)$. The minimal criteria for RLS were fulfilled by $8.3 \%$ of the German and $17.0 \%$ of the Australian patients $(\mathrm{p}=0.017$ ). The treating physicians, blinded to the patient answers, rated $4.3 \%$ of the German and $12.4 \%$ of the Australian patients as RLS cases. RLS prevalence was similar across subtypes of depression.

Discussion: In Germany, RLS is not more frequent in inpatients with manifest depression as compared to the general population. Possible reasons for the higher prevalence of RLS in depressive patients in Australia are discussed. RLS prevalence does not vary by subtype of depression.

\section{P2755}

\section{Automatic sleep scoring in normals and in individuals with neurodegenerative disorders according to new international sleep scoring criteria}

P. Jensen', H.B.D. Sørensen'1, P.J. Jennum ${ }^{2}$

'DTU Electrical Engineering, Technical University of

Denmark, Copenhagen, 'Danish Center for Sleep Medicine,

University of Copenhagen, Glostrup Hospital, Glostrup,

Denmark

Introduction: Reliable polysomnographic classification is the basis for evaluation of sleep disorders in neurological diseases.

Aim: To develop a fully automatic sleep scoring algorithm on the basis of a reproduction of new international sleep scoring criteria from the American Academy of Sleep Medicine (AASM).

Methods: A biomedical signal processing algorithm was developed, allowing for automatic sleep depth quantification of routine polysomnographic (PSG) recordings through feature extraction, supervised probabilistic Bayesian classification, and heuristic rule-based smoothing. The performance of the algorithm was tested using 28 manually classified day-night PSGs from 18 normal subjects and 10 patients with Parkinson's disease (PD) or multiple system atrophy (MSA). This led to quantification of automaticversus-manual epoch-by-epoch agreement rates for both normal and abnormal recordings.

Results: Resulting average agreement rates were $87.7 \%$ (Cohen's Kappa: 0.79) and 68.2\% (Cohen's Kappa: 0.26) in the normal and abnormal group, respectively. Based on an observed reliability of the manual scorer of $92.5 \%$ (Cohen's Kappa: 0.87 ) in the normal group and $85.3 \%$ (Cohen's Kappa: 0.73 ) in the abnormal group.

Conclusion: The developed algorithm was capable of scoring normal sleep with an accuracy around the manual inter-scorer reliability, it failed in accurately scoring abnormal sleep as encountered for the PD/MSA patients, which is due to the abnormal micro- and macrostructure pattern in these patients. 